\title{
Past, present and future: overview on histology and histopathology
}

\author{
Giuseppe Musumeci \\ Correspondence: g.musumeci@unict.it

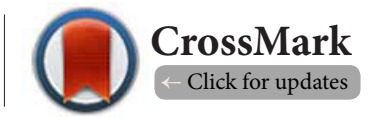

Department of Bio-medical Sciences, Anatomy and Histology Section, School of Medicine, University of Catania, Italy.

\section{Editorial}

With sincere satisfaction and pride, I present this first editorial of the Journal of Histology and Histopathology edited by myself. I know this is a very challenging task, assuming the editorial coordination of this journal, targeted to enhance the work of so many esteemed international experts as well as dear colleagues, who work on morphological research. A special thanks goes to our current editorial team (Sherif M Karam, Xueyong Zhu, Gjumrakch Aliev, Khin Thway, Han-Seung yoon, Paul Evans, George Perry and Khush Mittal) and the publishing group (Herbert Publications) that, day after day, thanks to their valuable contribution, make possible the growth of this journal. Reviewing a manuscript is time-consuming and unpaid, and often reviewers are bombarded with requests to review simultaneously from several journals. I hope to increase the number of editors of the editorial board members (with different geographical origin), to assure a rapid publication. My aim and that of all the other editors is that this journal will constitute a valuable tool, of both learning and research, to understand how modern histology and histopathology can be a fundamental bridge between molecular and anatomicalphysiological disciplines and how the structural organization of cells in tissues is inextricably linked to the functions that the pathological and normal tissues must perform. These concepts must constitute a significant part of imprinting training, necessary to help researchers to work in a more guided way, increasingly interested in a cellular approach to diseases and their related treatments. Finally, conscious of the fact that this journal can be considered a "system" subjected to the laws of evolution, we welcome criticism and suggestions for its improvement in the future. The purpose of this editorial was to explain my view on histology and histopathology of today, providing a brief overview from the past to the future.

\section{Histology}

Histology and Histopathology are often discussed and described together. In fact, the concept of histopathology cannot be separated from that of histology since understanding of normal histology is essential for histo-pathological interpretation. It is indeed obvious and necessary to prepare histology slides of a sample or specimen and examine them first in order to find out if the cells or tissue are healthy or diseased. Moreover, expert histo-pathologists should also be able to inform histologists about normal variations of tissue morphology, improving in this way histo-pathological interpretations. We could state then, that histology and histopathology are inter-dependent. In the $19^{\text {th }}$ century, histology was an eminent academic discipline in its own right and the first half of the $20^{\text {th }}$ century was a very productive period for new staining techniques in histology and histopathology. Indeed the 1906 Nobel Prize in Physiology or Medicine was awarded to histologists Camillo Golgi and Santiago Ramon y Cajal. They had conflicting interpretations of the neural structure of the brain based on differing interpretations of the same images. Cajal was appreciated for his correct theory and Golgi for the staining technique that he invented. Many of the centenary staining techniques in cell biology and histopathology are still used and continue to provide valuable diagnostic information. Histology is the study of the microscopic details and structures of biological cells and tissues, using light, fluorescence or electron microscopes, examining a thin slice (called a "section") of tissues, that have been previously prepared using appropriate processes called "histological techniques". The first microscope had been constructed in 1591 but had several optical problems. In 1673 Anton van Leeuwenhoek developed a simple microscope with a single lense but with improved magnification and resolution. The first microtome suitable for sectioning animal tissues was constructed in 1848. During the $19^{\text {th }}$ century paraffin wax was introduced for infiltration and support during sectioning. Over the years different laboratory substances were investigated for use as fixatives. Formalin was first used in 1893 and today is widely employed [1-3]. In order to better underline different biological structures, histological stains are often used to modify or enhance the colors of certain types of these biological structures differently from the others that may be located next to them or be in contact with them. There are many different histology stains selected according to the type of tissue to be observed. Some stains are more widely used, instead others are only used to study very specific types of biological tissues. One of the oldest stains was Prussian blue, introduced in 1774. Furthemore, Perl's reaction, discovered 
in 1867 , is still widely used to localize intracellular iron and uses just Prussian blue for the histochemical localization of hemosiderin in tissues. Hematoxylin and eosin (H\&E stain) is the most commonly used histology stain for light microscopy. Hematoxylin stains the nuclei within cells blue and eosin stains the cytoplasm of cells pink. $\mathrm{H} \& \mathrm{E}$ is a permanent histology stain, as opposed to a temporary stain. The hematoxylin and eosin staining techniques were first described in 1875-1878, with later modifications. Hematology took advantage from the introduction in the 1890s of Romanovsky-type staining for blood smears, including Giemsa's and May-Grunwald staining which are still fundamental in clinical practice. Louis B. Wilson was the first to develop a method using methylene dyes to stain fresh-frozen tissue of surgical specimens (1906). The periodic acid-Schiff (PAS) technique of McManus (1946) is still one of the most common diagnostic staining methods in histopathology, it superseded Best's carmine (1906) to stain polysaccharides and is widely used in liver and muscle disease [4-6]. Oil Red (ORO), introduced by French in 1926 highlights the presence of fat or lipids in fresh, frozen tissue sections. ORO is a fat soluble diazo dye, and is classified as one of the Sudan dyes used since the late 1800s. Feulgen stain (1924) is a staining technique used in histology to identify chromosomal material or DNA in cell specimens and has been the basis of many subsequent applications in cell biology. The Ziehl-Nielsen stain for Mycobacterium tuberculosis (1883) and Gram's stain for bacteria (1884) are examples of diagnostic bacteriological and pathological techniques, which are still used over a century since their discovery. Paul Ehrlich, who received the Nobel Prize in 1908 for his discovery and his work on "magic bullets", developed the use of dyes to combat disease i.e., methylene blue (1891) to fight malaria and trypan red (1904) against the trypanosomes. Trypan blue remains in widespread as a vital stain, particularly in highlighting cataracts during eye surgery [4-6]. These staining methods are generally inexpensive, reliable, fast, produce permanent preparations that are easy to interpret and archive, and deliver information for diagnoses that cannot be achieved by other means. For these reasons they remain useful and irreplaceable tools in the histology discipline.

\section{Histopathology}

Histopathology regards biological tissues and cells with their microscopic changes or abnormalities that can be the causes or the result of diseases. The main application of histopathology in clinical medicine, is in the examination of a biopsy (i.e., a surgical sample or specimen taken from patients possibly for diagnosis and screening of various tumors) by a specialist physician called a pathologist. The pathologist may be more accurately referred to as a histopathologist. However, for some histopathologists the microscopic examination of diseased tissues may be only a relatively minor part of their overall professional responsibilities. A pathologist or histopathologist studies specimens of cells and tissue samples removed from the patients, processed using special histological techniques (histological slides and sections prepared and stained in order to make the sample ready for observation with a microscope). Either a light microscope or an electron microscope may be used to examine histology slides. The first book on the specialization of histopathology techniques, entitled, "On the Nature and Structural Characteristics of Cancer" was written in 1838 by Johannes Müller. Enzyme histochemistry, electron microscopy, and polarizing microscopy have all become diagnostic tools during the last 50 years. Actually, the use of electron microscopy is rare, except for specific contexts or disciplines such as renal pathology. The use of immunohistochemistry, still under development with new antibodies and biomarkers, began in the 1980s and has revolutionized cancer diagnosis [1-3]. The histology laboratory experienced several changes in the mid 20th century when cryostats, enclosed tissue processors, plastic cassettes, and disposable knives were introduced. The emergence of immunohistochemistry in the 1980s was a revolution among the histopathology methods [1-3] and made obsolete the necessity for the use of electron microscopy. New techniques include flow cytometry, fluorescence in situ hybridization (FISH), DNA and genetics studies, proteomics, telepathology, and digital imaging. The field of proteomics will be widened by the discovery of new biomarkers and new immunohistochemical tests. These new tests must be accepted by the medical community, and therefore histology laboratories in various hospitals will have to work together to standardize their protocols. Telepathology will be implemented for consultation and diagnosis. However, technicians will have to be sure that a slide prepared in one laboratory when sent as a scan to another laboratory for diagnosis conforms to certain criteria. Thus, specimen collection, fixation, and processing will need to be consistent between laboratories. In less-developed countries these telepathology techniques and equipment will be of benefit to patients [1-3].

\section{Conclusion}

We can be proud that basic histological, histochemical and immuohistochemical methods have a very long and productive history and continue to give us useful information. We have an enormous debt to the pioneers who discovered stains for coloring tissues and combating disease together with subsequent techniques. These old methodologies still continue to play an important role in the histopathology laboratory and remain at the forefront of research in these disciplines with an enormous long-term impact in cell biology and molecular biology. Histology is the tool for accessing a specific knowledge of the microscopic organization of the organs, microscopic anatomy, which is essential to understand the histopathology for a possible diagnosis. Although today in the research field these disciplines may seem displaced by the in vitro study of cell biology, molecular biology, genetics studies and proteomics, in my opinion, remain a key to help and sustain, with the in 
vivo study of tissue and organs, an efficient clinical practice. In confirmation, it is known that histopathology is an essential tool in diagnosis and the experience of the histopathologist is prime and irreplaceable for the correct interpretation of the data obtained. Although immunohistochemical analyses and molecular biology are useful for diagnostic purposes, light microscopy remains preeminent in cytological and histological diagnosis on a daily basis. Hematoxylin and eosin stain is still the gold standard for diagnosis, also in malignancy diagnosis that is based on the interpretation of cytological and architectural features, while immunohistochemistry and molecular biology are ancillary tools which can provide useful information in confirming histologically-based diagnosis.

\section{Competing interests}

The author declares that he has no competing interests.

\section{Acknowledgement}

I thank Prof. Gaetano Magro from Department G.F. Ingrassia, Anatomic Pathology Section, University of Catania, Catania, Italy, for his kind support.

Publication history

Editors: Sherif M Karam, UAE University, Al-Ain UAE.

Khush Mittal, New York University School of Medicine, USA.

Received: 24-May-2014 Final Revised: 26-Jun-2014

Accepted: 27-Jun-2014 Published: 05-Jul-2014

\section{References}

1. Titford M. A Short History of Histopathology Technique.J Histotechnol. 2006; 29:99-110. | Article

2. Titford M. Progress in the development of microscopical techniques for diagnostic pathology. J Histotechnol. 2009; 32:9-19. I Pdf

3. Titford $M$ and Bowman B. What May the Future Hold for Histotechnologists? LabMedicine. 2012; 43:5-10. | Article

4. Coleman R. The impact of histochemistry--a historical perspective. Acta Histochem. 2000; 102:5-14. | Article | PubMed

5. Coleman R. The long-term contribution of dyes and stains to histology and histopathology. Acta Histochem. 2006; 108:81-3. | Article | PubMed

6. Coleman R. Eponyms in histology and histochemistry: do they still serve a purpose, or should they be abandoned in favor of standard noneponymous terminology? Acta Histochem. 2006; 108:241-2. | Article | PubMed

\section{Citation:}

Musumeci G. Past, present and future: overview on histology and histopathology. J Histol Histopathol.

2014; 1:5. http://dx.doi.org/10.7243/2055-091X-1-5 